\title{
Two new species of centipedes, Lithobius keelungensis sp. nov. and Lithobius (Monotarsobius) qingquanensis sp. nov., from Taiwan (Chilopoda, Lithobiomorpha, Lithobiidae)
}

\author{
J.L. CHAO ${ }^{1 *}$, K.S. LEE $^{2} \&$ H.W. CHANG ${ }^{3}$ \\ ${ }^{1}$ Jui-Lung Chao, Invertebrate Section, Biology Department, National Museum of Natural Science (NMNS), 1 Guancian Road, \\ Taichung 40453, Taiwan, R.O.C., E-mail: chaojuilung@gmail.com, *Corresponding author \\ ${ }^{2}$ Kwen-Shen Lee, Invertebrate Section, Biology Department, National Museum of Natural Science (NMNS), \\ 1 Guancian Road, Taichung 40453, Taiwan, R.O.C. \\ ${ }^{3}$ Hsueh-Wen Chang, Department of Biological Sciences, National Sun Yat-Sen University, \\ 70 Lien-Hai Road, Kaohsiung 804, Taiwan, R.O.C.
}

\begin{abstract}
Male secondary sexual characters are diverse in Taiwanese Lithobius. We describe two new species with their male secondary sexual characters, Lithobius (Ezembius) keelungensis sp. nov. and Lithobius (Monotarsobius) qingquanensis sp. nov.. In $L$. (E.) keelungensis, male $14-15^{\text {th }}$ femora and tibiae are markedly thick, the femora have a deep furrow on each dorsal surfaces, and the tibiae are oval, with a wide shallow excavation on each dorsal surfaces. In $L$. (M.) qingquanensis, a small wart-like outgrowth bearing about 15 slightly curved setae is present on the dorsoposterior surface of the male $15^{\text {th }}$ femur.
\end{abstract}

Keywords. Keelung, male secondary sexual character, taxonomy.

\section{INTRODUCTION}

$\mathrm{T}$ he centipede genus Lithobius Leach, 1814 is among the poorly studied taxa of Taiwan. Takakuwa (1939, 1941a, 1941b) described and recorded eight species of Lithobius from Taiwan. However, his specimens were destroyed in an air attack during the war in 1945. Wang $(1955,1956,1957,1959,1963)$ recorded the localities of seven species of Lithobius from Taiwan without descriptions, and we could not locate Wang's specimens in any collections. We studied new specimens of Lithobius from Taiwan, and deposited them at the National $\mathrm{Mu}$ seum of Natural Science (NMNS). Male secondary sexual characters are important characters in the taxonomy of Lithobius: several several longitudinally arranged long setae were present on the ventral surface of male $15^{\text {th }}$ tibia in Lithobius trichopus Takakuwa, 1939; a small tunnel at the top of a longitudinal excavation is present on the dorsal surface of $14^{\text {th }}$ tibia in male Lithobius ongi Takakuwa, 1939, and the tunnel and bottom of the excavation bear numerous small pores (Chao et al. 2018a); a large ventral swelling on the male $15^{\text {th }}$ femur in Lithobius (Monotarsobius) meifengensis Chao, Lee \& Chang, 2018, and the apical region of the swelling bearing numerous small pores (Chao et al. 2018b). We here describe two new species from Taiwan, Lithobius (Ezembius) keelungensis sp. nov. and Lithobius (Monotarsobius) qingquanensis sp. nov. using two other types of male secondary sexual characters.

\section{MATERIAL AND METHODS}

One and fifteen specimens, respectively, of the two new species treated below were collected from Keelung City and Hsinchu County, Taiwan. The specimens were examined by light microscopy (Leica MZ16) and SEM (Hitachi SU-1510). Type specimens are preserved in $75 \%$ alcohol and deposited in the Department of 
Biology, National Museum of Natural Science, Taichung, Taiwan. Terminology of the external anatomy follows Bonato et al. (2010). The following abbreviations are used in the text and tables: a-anterior, $\mathrm{C}$ - coxa, $\mathrm{F}$ - femur, $\mathrm{m}-$ median, $\mathrm{p}$ - posterior, $\mathrm{P}$-prefemur, $\mathrm{S} / \mathrm{SS}$ sternite/sternites; $\quad \mathrm{t}$-trochanter, $\quad \mathrm{T} / \mathrm{TT}$ tergite/tergites, $\mathrm{Ti}$ - tibia.

\section{TAXONOMY}

\section{Order Lithobiomorpha Pocock, 1895}

\section{Family Lithobiidae Newport, 1844}

Genus Lithobius Leach, 1814

\section{Subgenus L. (Ezembius) Chamberlin, 1919}

\section{Lithobius keelungensis sp. nov.}

(Figures 1-15)

Material examined. Holotype. $\hat{\sigma}$ (NMNS8103-001): forest floor, Hepin Island, Keelung City, Taiwan, $25^{\circ} 09.366^{\prime} \mathrm{N}$, $121^{\circ} 45.94 ' \mathrm{E}, 13 \mathrm{~m}$ in elevation, 12 Jan 2019 , leg. Jui-Lung Chao. Paratypes, $1 \delta^{\lambda}$ (NMNS8103-002): same data as holotype. Other material, 2ㅊํ, 2 우 (NMNS7843019, NMNS7843-020, NMNS7843-021, NMNS7843-022), same locality as holotype, 14 Jan 2018, leg. Jui-Lung Chao; 19 (NMNS8103-

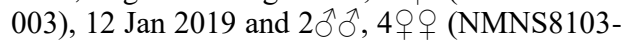
004), 08 Apr 2019, forest floor, Keelung City, $25^{\circ} 07.85^{\prime} \mathrm{N}, 121^{\circ} 43.72^{\prime} \mathrm{E}, 84 \mathrm{~m}$, leg. Jui-Lung Chao; $2 \delta^{\lambda}$ (NMNS8103-005), forest floor, Keelung City, $25^{\circ} 08.90^{\prime} \mathrm{N}, 121^{\circ} 46.73 \mathrm{\prime}$, $33 \mathrm{~m}$, 27 Jan 2018, leg. Jyh-Jong Cherng.

\section{Etymology. Refers to the type locality.}

Diagnosis. A Lithobius species, antennae with 20 articles; 7-9 ocelli arranged in three irregular rows $[1+2,3(4), 2(1)]$, posterior ocellus largest, two posterosuperior ocelli large, ventral seriate ocelli smallest; Tömösváry's organ larger than adjacent ocelli; $2+2$ coxosternal teeth; porodonts posterolateral to outer tooth; all tergites lacking posterior triangular projections; coxal pores $4-6$, round; male secondary sexual characters on $14-15^{\text {th }}$ : femora and tibiae mark- edly thick, $14-15^{\text {th }}$ femora with a furrow on each dorsal surface, male $14-15^{\text {th }}$ tibiae oval, with a wide shallow excavation on each dorsal surfaces; male gonopods with three long setae; female gonopods with $2+2$ sharp coniform spurs, point of terminal claw undivided, a small sharp lateral denticle on base of terminal claw.

Description. Body length: 11-13.5 mm. Body colour: dark brown (Figs. 1-2). Antennae with 20 articles; basal article width subequal to length, following articles markedly longer than wide; distal article much longer than wide, up to 3.4 times as long as wide; abundant setae on antennal surface, less so on basal articles, gradual increase in density to around fourth article, then more or less constant in number. Cephalic plate smooth, convex, width subequal to length, posterior marginal ridge moderately broader and weakly concave; setae scattered sparsely over whole surface (Fig. 7). 7-9 ocelli on each side $[1+2,3(4), 2(1)]$, one posterior, two dorsal, three or four middle and one or two ventral, arranged in three irregular rows; posterior ocellus largest, two posterosuperior ocelli large, ventral seriate ocelli smallest; ocelli domed, translucent, usually darkly pigmented (Figs. 3-4). Tömösváry's organ nearly rounded, situated at the anterolateral margin of the cephalic plate, larger than adjoining ocelli (Fig. 4). Forcipular coxosternite sub-trapezoidal, anterior margin narrow, external side slightly longer than internal side; median longitudinal cleft moderately deep; anterior border with $2+2$ large triangular coxosternal teeth, inner tooth slightly larger than outer one; porodonts moderately slender, setiform, posterolateral to the outermost tooth (Figs. 5-6); some scattered setae on the ventral side of coxosternite.

Tergites smooth, without wrinkles, backside slightly hunched; T1 generally trapeziform, posterior margin narrower than anterior margin, narrower than T3 and cephalic plate; T3 slightly narrower than cephalic plate; TT7, 8 and 10 broader than other tergites; T7 slightly rectangular, about 0.5 times as long as wide, posterior margin of $\mathrm{T} 7$ straight (Fig. 7); posterior margin of TT1, 3, 5 weakly concave, TT8, 10, 12 concave, T14 lateral deeply concave, middle straight (Figs. 8-9); TT1, 3 and 5 with continuous lateral and posterior 
marginal ridges, other tergites with discontinuous posterior marginal ridges; posterior angles of all tergites lacking triangular projections (Fig. 8); tiny setae scattered very sparsely over the surface.
Sternites narrower posteriorly, generally trapeziform, comparatively smooth, setae emerging from pores scattered very sparsely over the surface (Figs. 10-12).
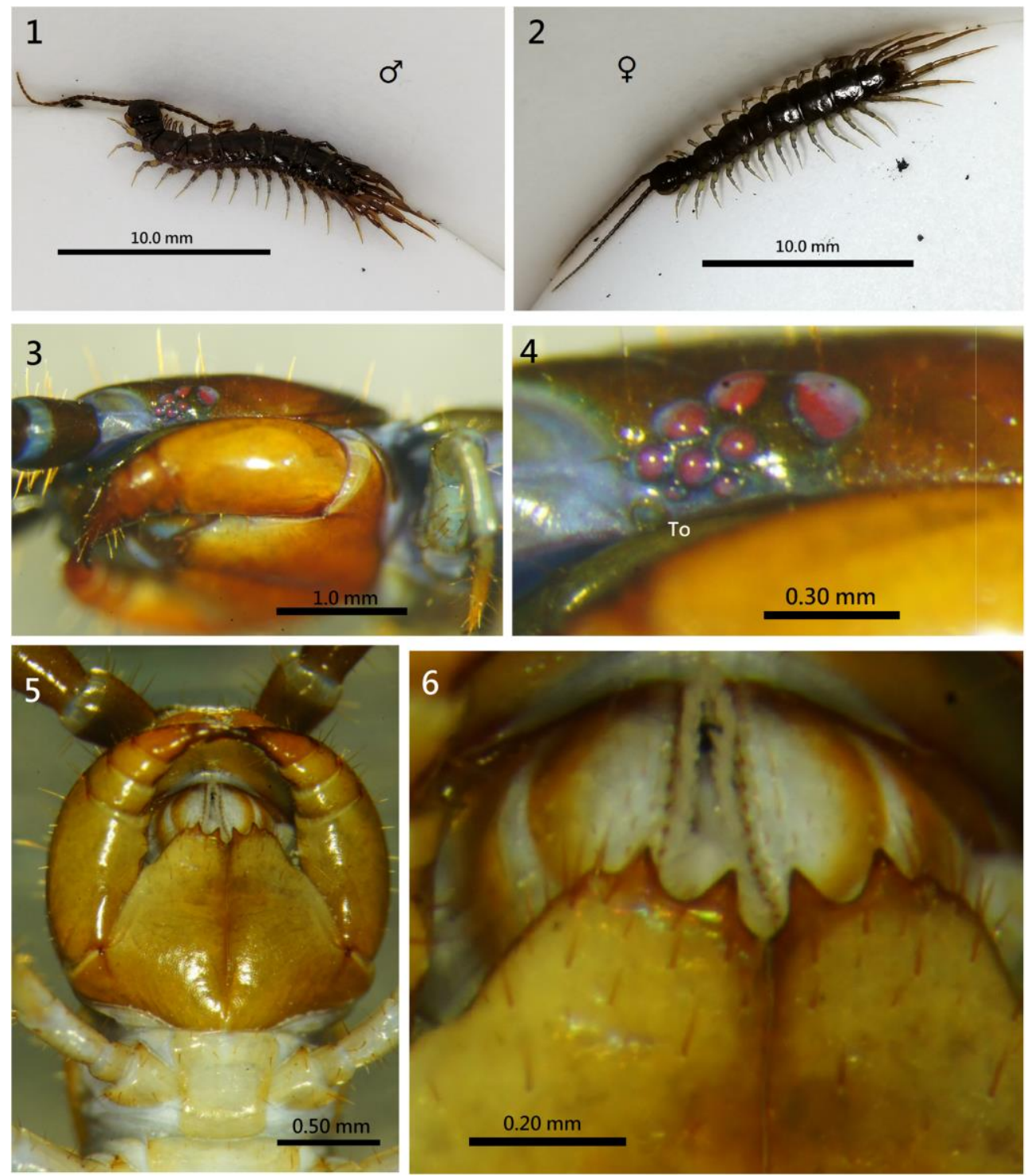

Figures 1-6. Lithobius (Ezembius) keelungensis sp. nov. $1=$ habitus, male, legs $14-15$ thick; $2=$ habitus, female; $3=$ lateral view of the head; $4=$ eight ocelli and Tömösváry's organ (To) on the left side; $5=$ ventral view of the head; $6=2+2$ coxosternal teeth and porodonts (1 \& 3-6: NMNS8103-001; 2: NMNS8103-004). 

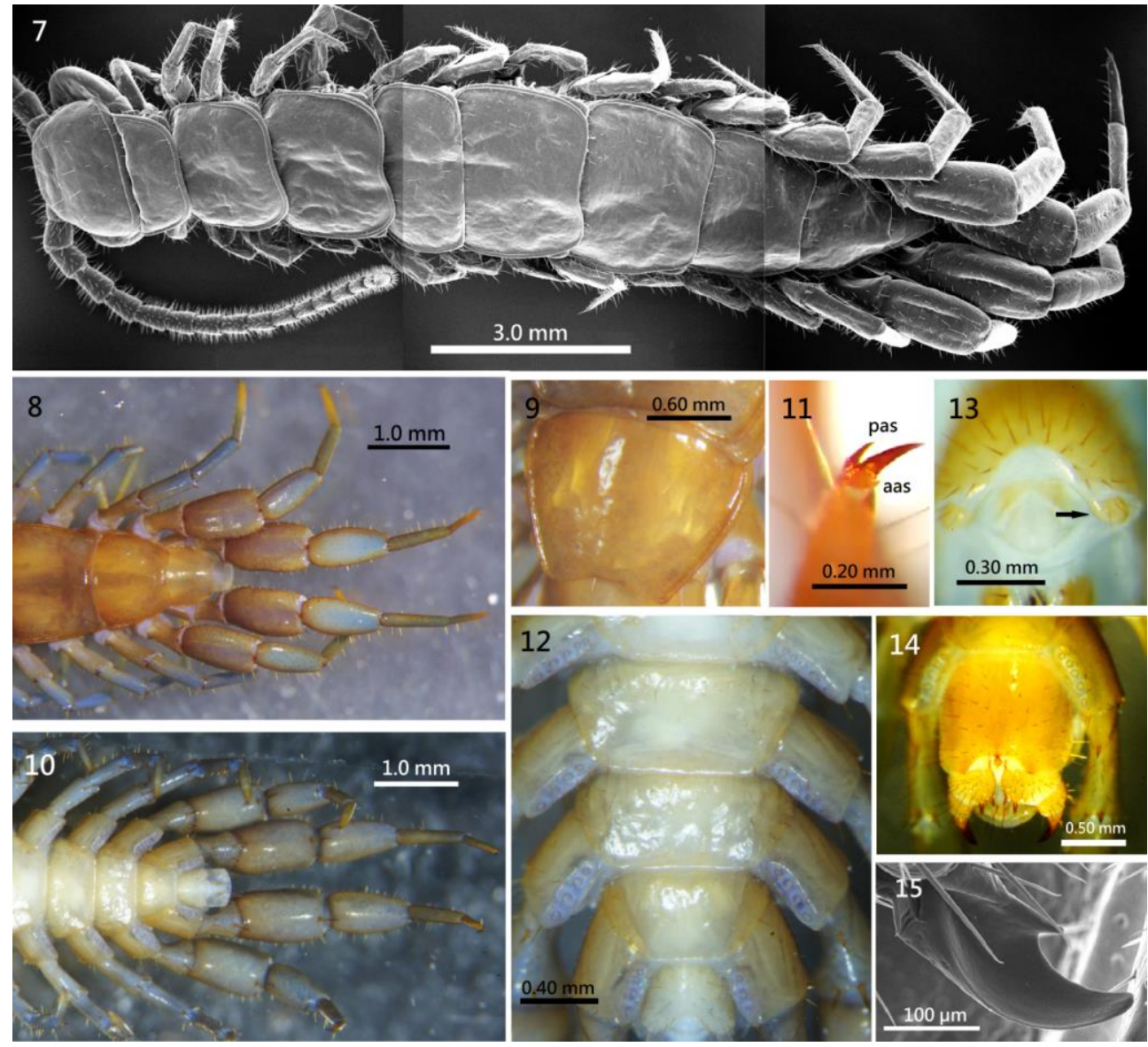

Figures 7-15. Lithobius (Ezembius) keelungensis sp. nov. $7=$ male, habitus, dorsal view by SEM; $8=$ posterior body on male, dorsal view; $9=14^{\text {th }}$ tergite; $10=$ posterior body on male, ventral view; $11=14^{\text {th }}$ claw with short anterior (aas) and long posterior accessory spines(pas); $12=$ coxal pores of $12-15^{\text {th }}$ leg; $13=$ male first genital sternite and gonopods (arrow); $14=$ female first genital sternite and gonopods; 15 = claw of female gonopod (7: NMNS8103-005; 8-13: NMNS8103-001; 14: NMNS8103-004; 15: NMNS8103-004).

Legs: tarsi well-defined on all legs; all legs with fairly long claws, curved ventrally; thick posterior accessory spines present on base of all claws; long and slender anterior accessory spines present on claws 1-13; very short anterior accessory spines on $14^{\text {th }}$ claws (Fig. 11); legs 15 lack anterior spine. Male secondary sexual characters (see below) present on thick $14^{\text {th }}$ and $15^{\text {th }}$ legs (Figs. $8-10$ ); female without secondary sexual characters. Leg plectrotaxy as in Table 1. Coxal pores $4-6$, round, inner pores small, coxal pore field set in a relatively shallow groove, margin of coxal pore-field with slightly eminence (Fig. 12).

Male secondary sexual characters: $14-15^{\text {th }}$ femora and tibiae markedly thick (Figs. 8-10), and $14-15^{\text {th }}$ femora with a deep furrow on each dorsal surface; male $14-15^{\text {th }}$ tibiae oval, with a wide shallow excavation on each dorsal surfaces (Figs. 7-8). Male first genital sternite: wider than long, usually well chitinized; posterior margin quite deeply concave between the gonopods, without a medial bulge; comparatively 
long setae scattered evenly on the ventral surface; male gonopods short and small, as a semispherical bulge with 3 long setae, apically well chitinized (Fig. 13).

Female first genital sternite: wider than long; posterior margin of the genital sternite deeply concave, with a medial bulge (Fig. 14); short to long setae sparsely scattered over the ventral surface of the genital segment. Female gonopod: first article fairly broad, bearing up to 23 long setae, arranged in four irregular rows; $2+2$ sharp coniform spurs, inner spur smaller (Fig. 14); second article with 7-9 rather long setae arranged in two irregular rows on its ventral side; third article usually with 2-3 long setae on its ventral surface; point of terminal claw undivided, a small sharp lateral denticle on the base of the terminal claw (Fig. 15).

Remarks. Wang (1956, 1959) recorded Chinobius sachalinus Verhoeff, 1937, with six specimens, Chinobius pachypedatus Takakuwa, 1941 with three specimens and Chinobius sulcipes (Attems, 1934) with two specimens from Taiwan, without any morphological descriptions. None of Wang's specimens could be located in Taiwan, and we consider Wang's records uncer- tain. According to the descriptions of Takakuwa (1941b), Matic (1973), Zalesskaja (1978) and Eason (1996), the male secondary sexual characters - markedly thick male $14-15^{\text {th }}$ femora and tibiae - are present in L. (Chinobius) sachalinus Verhoeff, 1937, L. pachypedatus Takakuwa, 1938 and L. sulcipes (Attems, 1927) from Japan and Eastern Russia. Takakuwa (1941b) redescribed L. pachypedatus with $1+5$ ocelli on each side, and male $15^{\text {th }}$ femora without any furrows, $L$. sulcipes with seven ocelli in two rows on each side, and male $14-15^{\text {th }}$ femora and $15^{\text {th }}$ tibiae with a deep furrow, and $L$. $(C$. $)$ sachalinus with nine ocelli on each side, male $15^{\text {th }}$ femora and tibiae with a furrow, and $14^{\text {th }}$ femora with a longitudinal arched swelling with dense setae. The same character-set of $L$. (C.) sachali$n u s$ is also found in Matic's key (1973) and Zalesskaja's description (1978). Furthermore, Zalesskaja (1978) and Eason (1996) added the female characters for $L$. (C.) sachalinus: $2+2$ spurs on the female gonopod, and gonopodal claw without denticles but with two or three large teeth on its medial ridge. However, L. keelungensis sp. nov. differs from $L$. pachypedatus, $L$. sulcipes and $L .(C$.) sachalinus by its different ocelli arrangement, female gonopodal claw and male $14-15^{\text {th }}$ legs as shown in Table 2.

Table 1. Leg plectrotaxy of Lithobius (Ezembius) keelungensis sp. nov.

\begin{tabular}{|c|c|c|c|c|c|c|c|c|c|c|}
\hline \multirow{2}{*}{ leg pair } & \multicolumn{5}{|c|}{ Ventral } & \multicolumn{5}{|c|}{ Dorsal } \\
\hline & C & $\mathbf{t}$ & $\mathbf{P}$ & F & $\mathbf{T i}$ & C & $\mathbf{t}$ & $\mathbf{P}$ & $\mathbf{F}$ & $\mathbf{T i}$ \\
\hline 1 & - & - & $\mathrm{p}$ & amp & $\mathrm{m}$ & - & - & $\mathrm{p}$ & $\mathrm{a}$ & $\mathrm{a}$ \\
\hline 2 & - & - & $\mathrm{p}$ & amp & $\mathrm{m}$ & - & - & $\mathrm{p}$ & ap & $\mathrm{a}$ \\
\hline 3 & - & - & $\mathrm{p}$ & amp & am & - & - & $\mathrm{p}$ & ap & $\mathrm{a}$ \\
\hline 4 & - & - & $\mathrm{mp}$ & amp & am & - & - & $\mathrm{p}$ & ap & ap \\
\hline 5-10 & - & - & $\mathrm{mp}$ & amp & am & - & - & ap & ap & ap \\
\hline 11-12 & - & - & $\mathrm{mp}$ & amp & am & - & - & amp & ap & ap \\
\hline 13 & - & - & amp & amp & am & - & - & amp & ap & ap \\
\hline 14 & - & $\mathrm{m}$ & amp & amp & am & - & - & amp & $\mathrm{p}$ & $\mathrm{p}$ \\
\hline 15 & - & $\mathrm{m}$ & amp & $\mathrm{am}$ & $\mathrm{a}$ & - & - & amp & $\mathrm{p}$ & - \\
\hline
\end{tabular}


Table 2. Main morphological characters of four species of Lithobius from East Asia.

\begin{tabular}{|c|c|c|c|c|}
\hline Species & $\begin{array}{c}\text { L. (E.) keelungensis sp. } \\
\text { nov. }\end{array}$ & L. (C.) pachypedatus & L. (C.) sulcipes & L. (C.) sachalinus \\
\hline $\begin{array}{l}\text { Description } \\
\text { from }\end{array}$ & This paper & $\begin{array}{c}\text { Takakuwa }(1938, \\
1941 b)\end{array}$ & Takakuwa (1941b) & $\begin{array}{l}\text { Takakuwa }(1941 b) \\
\text { Matic (1973) } \\
\text { Zalesskaja (1978) } \\
\text { Eason (1996) }\end{array}$ \\
\hline Antennae & 20 articles & 20-21 articles & 19-22 articles & 19-20 articles \\
\hline Ocelli & $\begin{array}{c}1+2,3,2 ; \text { arranged in } 3 \\
\text { rows }\end{array}$ & $\begin{array}{c}1+5 ; \text { arranged in } 2 \\
\text { rows }\end{array}$ & $\begin{array}{c}1+6 ; \underset{\text { rows }}{\operatorname{arranged}} \text { in } 2 \\
\text { row }\end{array}$ & $\begin{array}{c}1+5 \sim 8 ; \\
\text { rows }\end{array}$ \\
\hline $\begin{array}{l}\text { Male } 15^{\text {th }} \\
\text { femur }\end{array}$ & A deep dorsal furrow & No furrow & A deep dorsal furrow & A dorsal furrow \\
\hline $\begin{array}{l}\text { Male } 15^{\text {th }} \\
\text { tibia }\end{array}$ & A wide dorsal furrow & No furrow & A deep dorsal furrow & A dorsal furrow \\
\hline $\begin{array}{l}\text { Male } 14^{\text {th }} \\
\text { femur }\end{array}$ & $\begin{array}{c}\text { A dorsal furrow; absence } \\
\text { of dense setae on } \\
\text { dorsoposterior surface }\end{array}$ & $\begin{array}{c}\text { No furrow; absence of } \\
\text { dense setae on } \\
\text { dorsoposterior surface }\end{array}$ & $\begin{array}{c}\text { A deep dorsal furrow; } \\
\text { absence of dense se- } \\
\text { tae on dorsoposterior } \\
\text { surface }\end{array}$ & $\begin{array}{l}\text { A dorsal furrow; sev- } \\
\text { eral setae clustered on } \\
\text { dorsoposterior surface }\end{array}$ \\
\hline Coxal pore & $4-6$, round & $3-6$, round & $4-5$, round & $4-6$, round \\
\hline $\begin{array}{l}\text { Male } \\
\text { gonopod }\end{array}$ & 3 long setae & Several setae & No data & 3 long setae \\
\hline $\begin{array}{l}\text { Female } \\
\text { gonopod }\end{array}$ & $\begin{array}{c}2+2 \text { spurs; claw with a } \\
\text { large denticle on tip, a } \\
\text { small sharp lateral } \\
\text { denticle on base }\end{array}$ & $\begin{array}{c}3+3 \text { spurs; claw with } \\
\text { a denticle on tip, and } \\
\text { a small tooth on its } \\
\text { medial ridge }\end{array}$ & $\begin{array}{c}2+2 \text { spurs; claw } \\
\text { divided, biapiculate }\end{array}$ & $\begin{array}{c}2+2 \text { spurs; claw } \\
\text { without denticles, but } \\
\text { with two or three } \\
\text { large teeth on its } \\
\text { medial ridge }\end{array}$ \\
\hline
\end{tabular}

\section{Genus Lithobius Leach, 1814}

\section{Subgenus L. (Monotarsobius) Verhoeff, 1905}

\section{Lithobius (Monotarsobius) qingquanensis sp. nov.}

(Figures 16-25)

Material examined. Holotype, ô (NMNS81 03-006), garden, Qingquan, Hsinchu County, Taiwan, $24^{\circ} 34.36^{\prime} \mathrm{N}, 121^{\circ} 06.34^{\prime} \mathrm{E}, 570 \mathrm{~m}$ in elevation, 13 Mar. 2019, leg. Jui-Lung Chao.

Etymology. Refers to the type locality.

Diagnosis. A Lithobius (Monotarsobius) species with 17-18 elongate antennal articles; body colour brown; 3 ocelli arranged in one row, middle ocellus largest; Tömösváry's organ in front of ocelli, slightly smaller than anterior ocellus; $2+2$ coxosternal teeth; porodonts posterolateral to the outermost tooth; all tergites lack posterior triangular projections; TT1, 3 and 5 with continuous lateral and posterior ridges; posterior margin of TT1, 3, 5, 8, 10 and 12 weakly concave, posterior margin of T14 concave; tarsi fused on legs 1-13, well-defined on legs 14-15; male secondary sexual characters on dorsal surface of $15^{\text {th }}$ femur, a longitudinal excavation on central surface, and a small wartlike outgrowth with about 15 slightly curved setae on posterointernal surface; both $15^{\text {th }}$ tibia and $15^{\text {th }}$ tarsus I oval in male, with a wide shallow excavation on the dorsal surface; coxal pores 3433, round; male gonopods with two long setae.

Description. Body length: $8 \mathrm{~mm}$. Body colour: brown (Fig. 16). Antennae with 17-18 articles; most articles markedly longer than wide; 
distal article about 2.8 times as long as wide (Fig. 17); abundant setae on antennal surface, less so on basal articles, gradual increase in density to around fifth article, then more or less
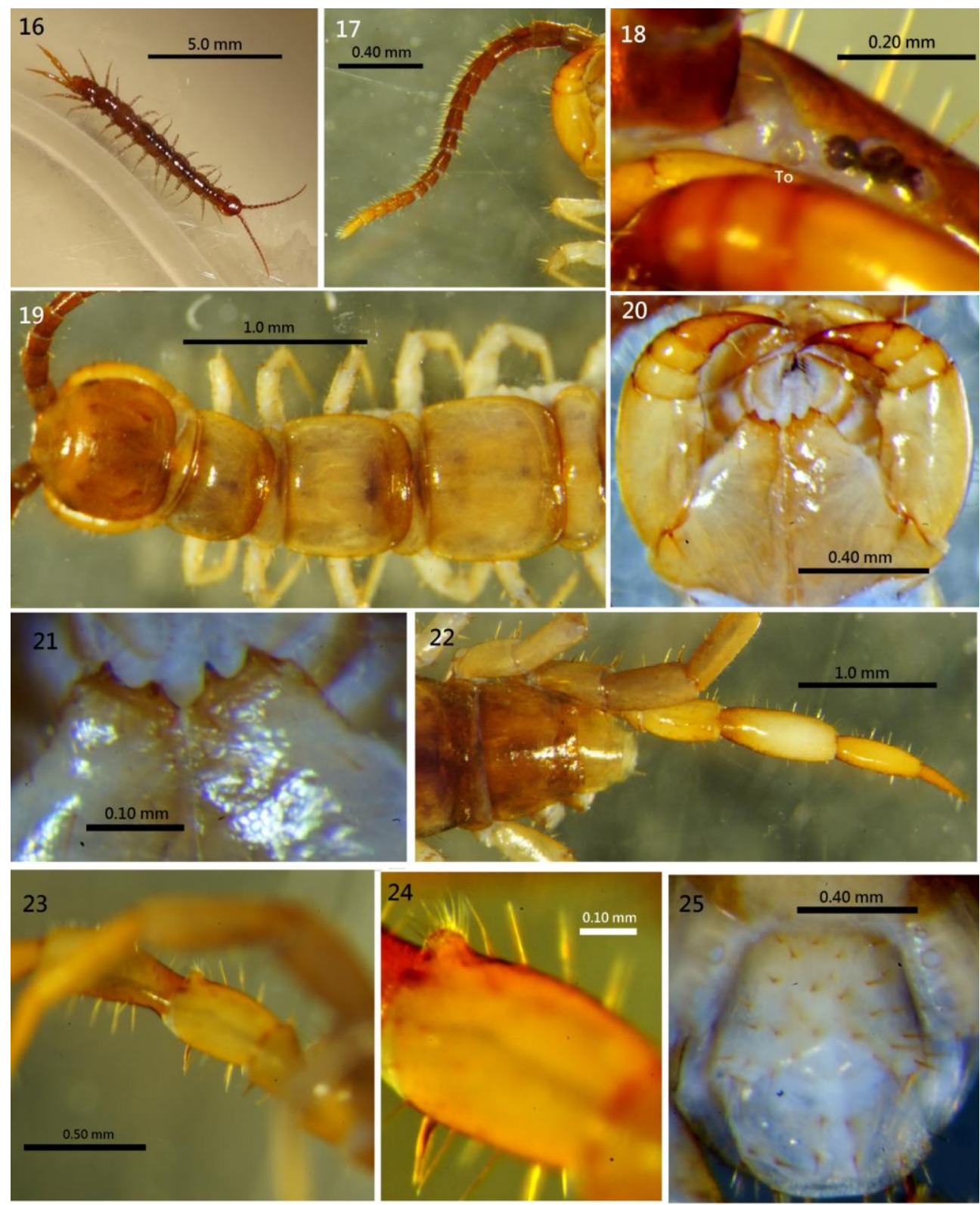

Figures 16-25. Lithobius (Monotarsobius) qingquanensis sp. nov. $16=$ habitus, male; $17=$ antennae; $18=$ three ocelli and Tömösváry's organ (To) on the left side; $19=$ anterior body, dorsal view; $20=$ ventral view of the head; $21=2+2$ coxosternal teeth and porodonts; $22=$ posterior body and $15^{\text {th }}$ leg, dorsal view; $23-24=15^{\text {th }}$ femur, lateral view; $25=$ male first genital sternite and gonopods (16-25: NMNS8103-006) 
constant in number. 3 ocelli on each side, arranged in one row, middle ocellus largest (Fig. 18); ocelli domed, translucent, usually darkly pigmented. Tömösváry's organ comparatively small, nearly rounded, in front of ocelli, slightly smaller than the anteriormost ocellus (Fig. 18). Cephalic plate smooth, convex, width subequal to length, posterior marginal ridge moderately broader and weakly concave (Fig. 19); setae scattered sparsely over the whole surface. Forcipular coxosternite with $2+2$ large triangular teeth, outer tooth slightly larger than inner one, the line of their apices recurved (Figs. 20-21); porodonts moderately slender, setiform, posterolateral to the outer tooth (Figs. 20-21); some scattered setae on ventral side of coxosternite.

Tergites smooth, without wrinkles, backside slightly hunched; $\mathrm{T} 1$ generally trapeziform, poste- rior margin narrower than anterior margin, narrower than T3 and cephalic plate (Fig. 19); TT1, 3 and 5 with continuous lateral and posterior ridges; posterior margin of TT1, 3, 5, 8, 10 and 12 weakly concave, posterior margin of T14 concave; all tergites lack posterior triangular projections; tiny setae scattered very sparsely over the surface.

Sternites narrower posteriorly, generally trapeziform, comparatively smooth, setae emerging from pores scattered very sparsely over the surface.

Legs: tarsi fused on legs 1-13, well-defined on legs 14-15; all legs with fairly long claws, curved ventrally; anterior accessory spine long and slender on legs 1-13, lacking on legs 14-15; thick posterior accessory spine on all legs; leg plectrotaxy as in Table 3.

Table 3. Leg plectrotaxy of Lithobius (Monotarsobius) qingquanensis sp. nov.

\begin{tabular}{|c|c|c|c|c|c|c|c|c|c|c|}
\hline \multirow{2}{*}{ leg pairs } & \multicolumn{5}{|c|}{ Ventral } & \multicolumn{5}{|c|}{ Dorsal } \\
\hline & C & $\mathbf{t}$ & $\mathbf{P}$ & $\mathbf{F}$ & Ti & C & $\mathbf{t}$ & $\mathbf{P}$ & $\mathbf{F}$ & $\mathbf{T i}$ \\
\hline 1 & - & - & - & - & - & - & - & $\mathrm{p}$ & $\mathrm{a}$ & $\mathrm{a}$ \\
\hline 2 & - & - & - & $\mathrm{m}$ & $\mathrm{m}$ & - & - & $\mathrm{p}$ & am & $\mathrm{a}$ \\
\hline $3-4$ & - & - & - & $\mathrm{m}$ & $\mathrm{m}$ & - & - & $\mathrm{p}$ & $\mathrm{a}$ & $\mathrm{a}$ \\
\hline 5 & - & - & - & $\mathrm{m}$ & $\mathrm{m}$ & - & - & $\mathrm{p}$ & ap & $\mathrm{a}$ \\
\hline 6 & - & - & - & $\mathrm{m}$ & $\mathrm{m}$ & - & - & $\mathrm{p}$ & amp & ap \\
\hline 7-9 & - & - & - & $\mathrm{m}$ & $\mathrm{m}$ & - & - & $\mathrm{p}$ & ap & ap \\
\hline 10 & - & - & $\mathrm{a}$ & $\mathrm{m}$ & $\mathrm{m}$ & - & - & $\mathrm{p}$ & ap & ap \\
\hline 11 & - & - & $\mathrm{a}$ & $\mathrm{m}$ & $\mathrm{m}$ & - & - & $\mathrm{mp}$ & ap & ap \\
\hline 12 & - & - & $\mathrm{mp}$ & $\mathrm{m}$ & $\mathrm{m}$ & - & - & $\mathrm{mp}$ & ap & ap \\
\hline 13 & - & - & $\mathrm{mp}$ & $\mathrm{m}$ & $\mathrm{m}$ & - & - & $\mathrm{mp}$ & $\mathrm{p}$ & ap \\
\hline 14 & - & $\mathrm{m}$ & $\mathrm{mp}$ & $\mathrm{m}$ & - & - & - & amp & - & - \\
\hline 15 & - & $\mathrm{m}$ & $\mathrm{mp}$ & $\mathrm{m}$ & - & - & - & amp & - & - \\
\hline
\end{tabular}

Male secondary sexual character on dorsal surface of $15^{\text {th }}$ femur: a longitudinal excavation on central surface (Fig. 22), several long setae scattered sparsely over the surface, and a small wart-like outgrowth bearing about 15 slightly curved setae present on dorsoposterior surface (Figs. 23-24); both $15^{\text {th }}$ tibia and tarsus I oval, with a wide shallow excavation on the dorsal surface (Fig. 22).
Coxal pores: 3433 , round, inner pores small, coxal pore field set in a relatively shallow groove, margin of coxal pore-field with slightly eminence (Fig. 25).

Male sternite 15: trapeziform, posterolaterally narrower than anterolaterally, posterior margin straight, long setae scattered sparsely over the surface (Fig. 25). Male first genital 
sternite: wider than long, usually well chitinized; posterior margin quite deeply concave between gonopods, without a medial bulge; comparatively long setae evenly scattered on ventral surface; male gonopods short and small, as a semi-spherical bulge with two long setae, apically slightly chitinized (Fig. 25).

Remarks. Murakami (1965) described a Lithobius (Monotarsobius) species from Japan, L. (M.) tuberculatus Murakami, 1965, with a male secondary sexual character, a wart-like outgrowth with several long curved setae on the dorsoposterior surface of male $15^{\text {th }}$ tibiae. Matic (1970) described two Lithobius (Monotarsobius) species from Korea, L. (M.) dziadoszi Matic, 1970 and $L$. (M.) riedeli, Matic, 1970. A wartlike outgrowth with several short setae on the dorsoposterior surface of $15^{\text {th }}$ femora is present in male $L$. (M.) dziadoszi, and a similar outgrowth with several short setae on the dorsoposterior surface of $15^{\text {th }}$ tibiae in male $L$. (M.) riedeli. However, L. (M.) qingquanensis sp. nov. differs from $L$. (M.) dziadoszi by its 3 ocelli arranged in one row, and Tömösváry's organ slightly smaller than the adjoining ocellus, contrasting with $L$. (M.) dziadoszi with 7 ocelli arranged in two irregular rows, and Tömösváry's organ larger than the adjoining ocellus. $L .(M$. qingquanensis sp. nov. differs from $L$. (M.) tuberculatus and $L$. $(M$.) riedeli by its wart-like outgrowth on $15^{\text {th }}$ femora, contrasting with $L$. $(M$.) tuberculatus and $L$. $(M$.) riedeli with their wart-like outgrowth on $15^{\text {th }}$ tibiae.

\section{Key to the known Taiwanese species of the genus Lithobius Leach, 1814}

1. Posterior angles of TT9, 11 and 13 with triangular projecttions ................................................

- Posterior angles of TT9, 11 and 13 without triangular projecttions

2. Male secondary sexual characters present on leg 14 or $15 \ldots$

.

- Male secondary sexual characters absent L. bidivisa Takakuwa, 1939

3. Posterior angles of $\mathrm{T} 7$ with a triangular projection; a small tunnel at top of a longitudinal excavation on dorsal surface of male $14^{\text {th }}$ tibia ..................... ongi Takakuwa, 1939

- Posterior angles of T7 without projections; about 40 long setae longitudinally arranged on ventral face of male $15^{\text {th }}$ tibia, most setae concentrated in posterior part

..L.trichopus Takuwa, 1939
4. Tarsi fused on legs 1-13, well-defined on legs 14-15 ....... .5 , subgenus L. (Monotarsobius)

- Tarsi well-defined on all legs ......9, subgenus L. (Ezembius)

5. Male secondary sexual characters present on leg 15 ........6

- Male secondary sexual characters absent ....................7

6. A large swelling on ventral surface of male $15^{\text {th }}$ femur, apical region of swelling bearing numerous small pores ..... ..................(M.) meifengensis Chao, Lee \& Chang, 2018

- A small wart-like outgrowth bearing ca. 15 slightly curved setae present on dorsoposterior surface of male $15^{\text {th }}$ femur . .L. (M.) qingquanensis sp. nov.

7. 2222 coxal pores; terminal claw of female gonopod divided, biapiculate .......... (M.) obtusus Takakuwa, 1941

-3-5 coxal pores; terminal claw of female gonopod undivided

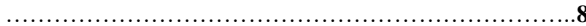

8. 5555 coxal pores; a small sharp tooth on the base of terminal claw of female gonopod L. (M.) ramulosus Takakuwa, 1941

- 3-4 coxal pores; terminal claw of female gonopod with irregular internal and external ridges

L. (M.) holstii (Pocock, 1895)

9. Male secondary sexual characters present both on leg 14$15: 14-15^{\text {th }}$ femora and tibiae thick, $14-15^{\text {th }}$ femora with a furrow on each dorsal surfaces; female gonopods with $2+2$ spurs ........................... L. (E.) keelungensis sp. nov.

- Male secondary sexual characters absent; female gonopods with $3+3$ spurs

10. Female gonopodal claw bipartite, a large denticle on tip, a small sharp lateral denticle on base of terminal claw ..L (E.) bidens Takakuwa, 1939

- Female gonopodal claw undivided, without a lateral denticle ..L. (E.) lineatus Takakuwa, 1939

Acknowledgements - We are grateful to Dr. Gregory D. Edgecombe for everlasting help during our study. Thanks also to Mr. Jyh-Jong Cherng for his specimens, to Mr. Shih-Chen Chang for translating the Japanese literatures, and to Ms. Shao-Kang Hu for preparing the SEM micrographs. We are deeply obliged to Prof. Sergei Golovatch, Prof. Huiqin Ma, Dr. Carlos Alberto Martinez-Muñoz and Dr. Alexandr Evsyukov for their help with literature.

\section{REFERENCES}

Bonato, L., EdGecombe, G.D., Lewis, J.G.E., Minelli. A., Pereira, L.A., Shelley, R.M. \& ZAPPAROLI, M. (2010): A common terminology for the external anatomy of centipedes (Chilopoda). ZooKeys, 69: 17-51.

doi: $\underline{10.3897 / \text { zookeys.69.737 }}$

CHAO, J.L., LEE, K.S. \& CHANG, H.W. (2018a): Neotype designation and redescription of the centipede Lithobius ongi Takakuwa, 1939 (Chilopoda, 
Lithobiomorpha, Lithobiidae). Collection and Research, 31: 63-69.

CHAO, J.L., LEE, K.S. \& CHANG, H.W. (2018b): Lithobius (Monotarsobius) meifengensis, a new species of centipede from high altitude forest in central Taiwan (Chilopoda, Lithobiomorpha, Lithobiidae). ZooKeys, 741: 181-192. doi: 10.3897/zookeys.741.21036

EASON, E.H. (1996): Lithobiomorpha from Sakhalin Island, the Kamchatka Peninsula and the Kurile Islands. Arthropoda Selecta, 5(3/4): 117-123.

MATIC, Z. (1970): Contribution à la connaissance des Lithobiides (Chilopoda, Lithobiomorpha) de Corée. Annales Zoologici Warszawa, 28: 55-63.

Matic, Z. (1973): Revision du genre Chinobius Verhoeff, avee des descriptions de trios espèces nouvelles (Chilopoda, Lithobiidae). Annales Zoologici Warszawa, 30: 33-47.

MuraKami, Y. (1965): Postembryonic development of the common Myriapoda of Japan. XIX. Two new species of Monotarsobius (Chilopoda: Lithobiidae). Zoological Magazine, 74: 69-75.

TAKAKUWA, Y. (1938): Über neue Art von Monotarsobius und von Lithobius aus Japan. Zoological Magazine, 50(11): 456-461.

TAKAKUWA, Y. (1939): Über Japanische LithobiusArten. Transactions of the Sapporo Natural History Society, 16(1): 29-30, 36-37.

TAKAKUWA, Y. (1941a): Über Einige Japanische Lithobiiden. Transactions of the Natural History Society of Formosa, 31(213): 292-297.
TAKAKUWA, Y. (1941b): Class Chilopoda, Epimorpha, Lithobiomorpha. Fauna Nipponica, Vol. 9 Fas. 8 No. (3). Sanseido Book Store, Tokyo, 104 pp..

WANG, Y.H.M. (1955): Serica 1a: Records of myriapods on Formosa with description of new species. Quarterly Journal of the Taiwan Museum, 8: 1316.

WANG, Y.H.M. (1956): Serica 1e: Records of myriapods on Formosa with description of new species (2). Quarterly Journal of the Taiwan Museum, 9: 155-159.

WANG, Y.H.M. (1957): Serica 1f: Records of myriapods on Taiwan Islands (3) - Pescadore Islets, Kao-Yung, Pingtung, Changhua and Taipei. Quarterly Journal of the Taiwan Museum, 10: 23-29.

WANG, Y.H.M. (1959): Serica 1j: On Chilopoda from Taiwan with a new Lithobid. Quarterly Journal of the Taiwan Museum, 12: 195-199.

WANG, Y.H.M. (1963): Serica 1q: Millipedes and Chilopoda of Quemoy, Fukien Province and Taiwan Island, Botel Tobago (Lan Yu), Taiwan province and of Singapore. Quarterly Journal of the Taiwan Museum, 16: 89-96.

ZALESSKAJA, N.T. (1978): Identification book of the lithobiomorph centipedes of the USSR (Chilopoda: Lithobiomorpha). Moscow, Nauka Publ. House, 212 pp. 